\title{
Thermally Activated Deformation Behavior of ufg-Au: Environmental Issues During Long-Term and High-Temperature Nanoindentation Testing
}

\author{
VERENA MAIER, ${ }^{1,4}$ ALEXANDER LEITNER, ${ }^{2,3}$ REINHARD PIPPAN, ${ }^{1}$ \\ and DANIEL KIENER ${ }^{2}$ \\ 1.-Erich-Schmid-Institute for Materials Science, Austrian Academy of Sciences, Jahnstr. 12, \\ 8700 Leoben, Austria. 2.-Department Materials Physics, Montanuniversität Leoben, Jahnstr. 12, \\ 8700 Leoben, Austria. 3.-Materials Center Leoben, Rosenegger Str. 12, 8700 Leoben, Austria. \\ 4.-e-mail: verena.maier@oeaw.ac.at
}

For testing time-dependent material properties by nanoindentation, in particular for long-term creep or relaxation experiments, thermal drift influences on the displacement signal are of prime concern. To address this at room and elevated temperatures, we tested fused quartz at various contact depths at room temperature and ultra-fine grained ( $\mathrm{ufg}$ ) $\mathrm{Au}$ at various temperatures. We found that the raw data for fused quartz are strongly affected by thermal drift, but corrected by use of dynamic stiffness measurements all the datasets collapse. The situation for the ufg Au shows again that the data are only useful with drift correction, but with this applied it turns out that there is a significant change of elastic and plastic properties when exceeding $200^{\circ} \mathrm{C}$, which is also reflected by an increasing strain rate sensitivity.

\section{INTRODUCTION}

Due to their outstanding sensitivity regarding localized mechanical data, nanoindentation experiments have become quite popular in recent years and have been very successful in bringing further insights into the framework of small-scale deformation mechanisms. ${ }^{1,2}$ By improving different indentation methods, and by progressing from quasi-static to rate-dependent testing protocols, reliable and reproducible data on time-dependent processes can nowadays be acquired for different materials and microstructures; for example, enabling one to address thermally activated processes on a local scale. ${ }^{3}$ Thus, it has become possible to study the origin of rate-dependent properties on a microstructure-based level. However, the desired extension to harsh environments in terms of temperature,${ }^{4-7}$ atmosphere,${ }^{8}$ or other media, ${ }^{9}$ is still at the beginning of their development. This requires careful experimental design and detailed knowledge about the indentation system itself, as subtle changes in the testing system over time or temperature will affect the determined properties. Of particular importance is the notion that drift rates are not constant over long-term experiments, ${ }^{3}$ a common assumption in drift correction schemes that should be critically considered in long-term or high-temperature (HT) experiments. Besides the different instrument designs, described recently by Wheeler et al., ${ }^{10}$ the selection of the correct indenter tip and indenter material is essential. In several studies, it has been shown that, with increasing the testing temperature, interactions between sample and tip take place, which can result in dissolution of the tip material, or oxide or carbide formation, thus degrading the initially well-defined tip shape. ${ }^{11}$ Moreover, the environmental conditions are of great importance, since surface oxides might significantly influence the experimental results. ${ }^{12} \mathrm{~A}$ great advantage is therefore the combination of HT testing and a vacuum environment, as published by Korte et al. ${ }^{6}$ and Wheeler et al., ${ }^{7}$ in order to minimize oxidation and also thermal drift. Another way to minimize thermal drift influences would be the use of a reference tip on the sample surface. ${ }^{13}$ This, 
however, requires uniformly flat samples, which poses some limitations to general indentation experiments.

With regard to materials properties, the time-dependent deformation behavior of highly deformed and thus ultrafine-grained (ufg) materials has been of great interest within the last decade, since these materials can combine strength and toughness, ${ }^{14}$ but also exhibit enhanced rate-dependent properties. ${ }^{15}$ Applying different severe plastic deformation processes such as equal channel angular pressing (ECAP), accumulative roll bonding (ARB) or high pressure torsion (HPT), a fine-grained microstructure corresponding to the applied deformation strain can be reached. However, there is up to now a lack of knowledge and understanding of the dominating deformation processes. ${ }^{15-19}$ For face-centered cubic materials, it has been reported that the strain rate sensitivity, which describes the change in hardness/stress in response to the applied strain rate, is intensified for fine-grained structures. ${ }^{15,20}$ This behavior has been discussed in close relationship with thermally activated dislocation annihilation processes at high-angle grain boundaries, ${ }^{15,21,22}$ but also sometimes in context with grain boundary sliding, especially during localized hardness and nanoindentation testing. Overall, these studies are mostly performed at room temperature, and only in a very limited number of cases at elevated temperatures. $^{23-25}$ Thus, a final discussion about the dominating factors is hard to conclude at the present state.

In this paper, we will focus on both the possible influences of experimental thermal drift issues on mechanical properties, at room and elevated temperatures, and also on the local deformation behavior, in terms of strain rate sensitivity, of the noble metal gold in an ufg condition also at room and elevated temperatures. Fused quartz (FQ), which is a standard calibration material, was chosen for a reference material, and several series of nanoindentation long-term creep/relaxation experiments were performed at room temperature for up to $2 \mathrm{~h}$ and also for varying indentation depths. These will be used to evaluate the possible influence of the applied indentation depth, thus the potentially changing heat flow through the contact area on thermal drift and thermal activation parameters determined by relaxation and creep kinds of indentation experiments. Moreover, elevated temperature nanoindentation experiments will be shown for ufg-Au. This material choice was guided by the fact that the rather soft noble metal eliminates concerns of sample oxidation, tip interaction and tip modifications by wear. Thus, we again aim to study only temperature-related influences on material properties, without complications from other potentially influencing factors. We show that, while standard material parameters such as hardness and Young's modulus can be easily determined even at elevated temperatures, long-term experiments are very prone to be influenced by thermal changes, or contact heterogeneities, which will be discussed in detail.

\section{EXPERIMENTAL}

Ufg-Au disks with a diameter of $8 \mathrm{~mm}$ and $0.8 \mathrm{~mm}$ in thickness were produced via a powder metallurgical HPT route,${ }^{12,26,27}$ in which spherical Au powders with a diameter of $\sim 7 \mu \mathrm{m}$ and purity of 99.96\% were compacted by HPT anvils and subsequently subjected to the severe plastic shear deformation.

Cross-sections of the ufg-Au disks were prepared for metallographic examinations and nanoindentation testing. The specimens were mechanically ground, subsequently polished with diamond suspension down to $1 \mu \mathrm{m}$, and finally electrolytically polished in order to remove any potentially remaining deformation layer. Subsequently, the grain structure was analyzed using the electron backscatter diffraction (EBSD) technique in a scanning electron microscope (Leo1525; Zeiss, Oberkochen, Germany). The median grain size of the ufg material before and after HT testing was evaluated using the automated grain determination routine of the EBSD software OIM TM data analysis (EDAX, Mahwah, USA). A misorientation angle of $15^{\circ}$ was set to differentiate small-angle from high-angle boundaries at a step size of $15 \mathrm{~nm}$.

Nanoindentation experiments were conducted using a Nanoindenter G200 (Keysight Technologies, USA) equipped with a continuous stiffness measurement (CSM) unit and a three-sided Berkovich pyramid [material selection: for room temperature (RT), diamond (MicroStar, USA); for elevated temperatures (HT), Sapphire (Synton, Switzerland)]. Machine stiffnesses and tip shape calibrations were performed at room temperature according to the Oliver-Pharr method, ${ }^{28}$ and nanoindentation testing was carried out at room temperature $\left(28^{\circ} \mathrm{C}\right.$; room not air-conditioned) as well as at high temperatures of up to $400^{\circ} \mathrm{C}$. Elevated testing temperatures were realized using a Laser Heating Stage (SurfaceTec, Hückelhoven, Germany), in which tip and sample are independently laser-heated to adjust and stabilize the contact temperature, minimize thermal drift influences, and guarantee a welldefined homogenous temperature distribution during the entire indentation process. Moreover, during the HT experiments, the whole system is actively water-cooled to $18^{\circ} \mathrm{C}$, including the $\mathrm{HT}$ sample tray as well as a $\mathrm{Cu}$ cooling shield which is arranged around the heated tip in order to protect the indenter head from thermal influences. In addition, an inert gas environment (forming gas: $\mathrm{N}_{2}$ containing $5 \% \mathrm{H}_{2}$ ) was created by two separately controlled valves that allow the individual regulation of the gas flow at the sample tray and in the coolingshield, thereby creating an oven-like, gas flooded 
volume around the tested sample. Obviously, for materials prone to oxidation, this would also prevent oxide formation. Finally, the initial thermal drift for all testing temperatures was set to $<0.3 \mathrm{~nm} / \mathrm{s}$ before starting the experiments, and the actual drift rates were determined previously for each indentation array, with typical values in the range of $0.1 \mathrm{~nm} / \mathrm{s}$ or better for all temperatures.

In terms of indentation protocols, standard constant strain rate (cSR-CSM) experiments $\left(0.025 \mathrm{~s}^{-1}\right)$ were carried out up to $2500 \mathrm{~nm}$ indentation depth. Furthermore, the local strain rate sensitivity (SRS) was measured using nanoindentation strain-rate jump tests, ${ }^{3,25,29}$ applying reversible strain rate changes from $0.025 \mathrm{~s}^{-1}$ to $0.005 \mathrm{~s}^{-1}$, or $0.0025 \mathrm{~s}^{-1}$. The rate changes were performed at $500 \mathrm{~nm}$ and $1500 \mathrm{~nm}$, respectively, and back to the initial strain rate at $1000 \mathrm{~nm}$ and $2000 \mathrm{~nm}$ indentation depth. The chosen strain rates are equivalent to indentation strain rates of $0.05 \mathrm{~s}^{-1}, 0.01 \mathrm{~s}^{-1}$ and $0.005 \mathrm{~s}^{-1}\left(\dot{h} / h=\frac{1}{2} \dot{P} / P\right)$, respectively. ${ }^{30}$ For all strain rate controlled tests, the CSM frequency was set to $45 \mathrm{~Hz}$ and a harmonic amplitude of $2 \mathrm{~nm}$ was superimposed. At room temperature, six, and at elevated temperatures, four, indentations were performed for each indentation method and temperature. For long-term indentation relaxation tests, a procedure detailed in $^{3,23}$ was used, which is based on ideas described in. ${ }^{31,32}$ Therefore, a strain rate-controlled indentation loading segment was performed to a preset relaxation start displacement, varying between $200 \mathrm{~nm}$ and $2000 \mathrm{~nm}$ for $\mathrm{FQ}$, and at a fixed value of $1000 \mathrm{~nm}$ for ufg-Au. Afterwards, the apparent raw load was held constant for $2 \mathrm{~h}$ (RT experiments) and 30 min (elevated temperatures), while the CSM unit was continuously recording the contact stiffness during the entire holding segment with an amplitude of $2 \mathrm{~nm}$ and $45 \mathrm{~Hz}$. Since the resultant, original displacement data are greatly influenced by varying thermal and experimental drift over time, the raw data were dynamically corrected for the actual drift rate using the measured contact stiffness and assuming a constant reduced modulus (determined during the indentation segment) (for further details of the correction method, the reader is referred $\left.t^{3,23}\right)$. Since the original stiffness data showed some homogenous scatter, the corrected displacement and hardness values were smoothed by a three-parameter power-fit $\left(y=a+b \cdot x^{c}\right)$ using the SigmaPlot software. Resultant creep rates were calculated using $\dot{\varepsilon}_{\text {relaxation }}=\dot{h} / h$, and the true hardness, based on the contact stiffness, was evaluated via $H=P / A_{\mathrm{c}-\mathrm{cor}}$. For very shallow indentation depths, the CSM amplitude could lead to a loss of contact between sample and tip. ${ }^{33}$ However, as our relaxation experiments started from indentation depths of at least $200 \mathrm{~nm}$, we do not expect such influences.
To quantify the acting thermally activated processes, reflected by strain rate-dependent changes in hardness, the local SRS, $m$, can be determined as $m=\partial \ln H / \partial \ln \dot{\varepsilon}$. For strain rate jump tests, this leads to single data points as a function of material hardness, $H$, while for relaxation experiments continuous $m$ values over $H$ can be calculated. ${ }^{3,23}$

\section{THERMAL DRIFT ISSUES DURING ROOM TEMPERATURE NANOINDENTATION: STRAIN RATE SENSITIVITY OF FUSED SILICA}

The measured indentation depth during longterm nanoindentation experiments is highly influenced by different factors. Figure 1a shows experiments on fused silica that lasted for $2 \mathrm{~h}$ each, where the load hold segment was started at different indentation depths of $200 \mathrm{~nm}, 500 \mathrm{~nm}, 1000 \mathrm{~nm}$, and $2000 \mathrm{~nm}$, and the subsequent changes in the displacement were recorded continuously. Obviously, for all different starting indentation depths, the original displacement data differ significantly, both for different creep starting depths and for different indents at the same condition, and do not show any general accordance to each other. For example, the maximum indentation depth between two tests starting at the same depth varies significantly, especially pronounced for the more shallow $200 \mathrm{~nm}, 500 \mathrm{~nm}$, and $1000 \mathrm{~nm}$ creep experiments (note the different scaling on the $y$-axis of Fig. 1a). This indicates that there is no clear correlation between contact area and the extent of thermal drift influence. Moreover, the displacement data show a wavy, irregular behavior over the 2-h time period, confirming some environmental influences during displacement recording. However, the quantification of the thermal drift, which is determined at the end of each indent, only gives values between $-0.003 \mathrm{~nm} / \mathrm{s}$ and $-0.061 \mathrm{~nm} / \mathrm{s}$ for all different depths, showing thereby no clear relationship between any testing parameters. Note that uniform drift over $2 \mathrm{~h}$ would result in displacements in the range of 20-440 $\mathrm{nm}$. Notably, these values again do not correlate with the raw displacements during the hold segment, proving that the final drift is not indicative for the whole experiment, although this is commonly assumed. However, correcting the displacement data by using the continuously measured contact stiffness as outlined before, for each different starting displacement, both curves are perfectly alike and lie on top of each other in Fig. 1a.

To quantify the increase of indentation depth during the hold period, and also the possible error that influences the data without correction, we note first that all shown diagrams represent a displacement range from the start of the creep segment to a $30 \%$ displacement increase. Due to the self-similarity of the pyramidal Berkovich tip, one would in fact expect that all data should be similar and independent of the initial indentation depth, as 

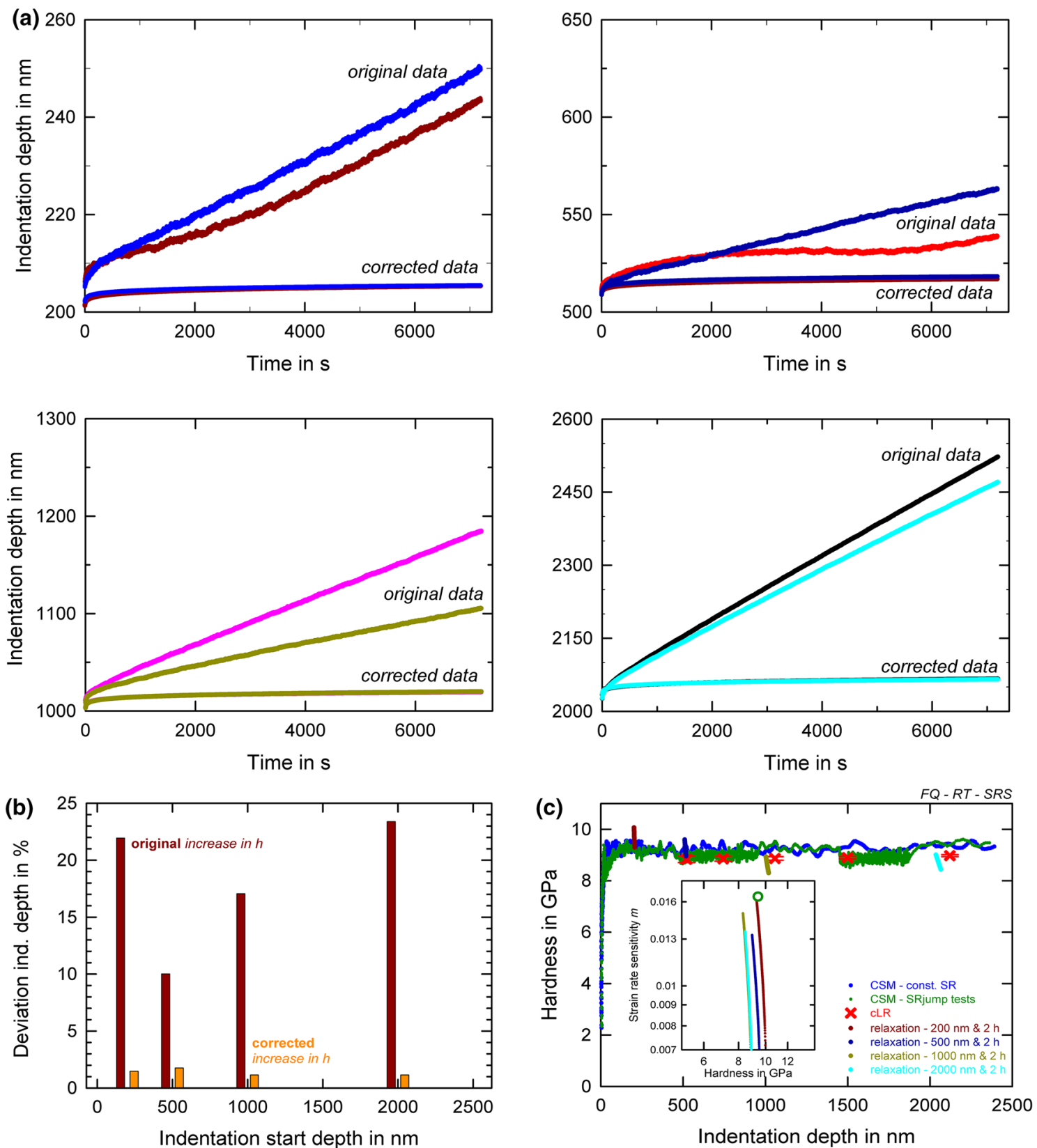

Fig. 1. Environmental issues during long-term nanoindentation testing on fused silica at room temperature. (a) Raw data and drift-corrected creep displacement versus $2 \mathrm{~h}$ constant load time for different indentation depths $(200 \mathrm{~nm}, 500 \mathrm{~nm}, 1000 \mathrm{~nm}$, $2000 \mathrm{~nm}$, from left to right). All $y$-axis represent an increase of $30 \%$ of the initial preset indentation depth. (b) Percentage of displacement increase for single indentations; original (red) and corrected (yellow) indentation data. (c) Hardness versus indentation depth for different indentation methodologies (cSR-CSM, strain rate jump, ${ }^{3}$ cLR as well as relaxation tests). The corresponding strain rate sensitivity is shown as inset.

such material properties should be independent of the analyzed volume. For the original data, this is clearly not the case, strong fluctuations and varying trends are observed. However, after correcting for drift-attributed displacement, the creep response of the material under the self-similar tip is clearly the same, independent of initial creep depth, and applied load, respectively, as shown in Fig. 1a. The relative deviation of indentation depth after $2 \mathrm{~h}$ indentation relaxation is shown in Fig. 1b. Here, the percentage of indentation depth increase in respect to the start displacement is plotted over the indentation start depth. For the corrected data, the deviations are depth-independent as would be expected and show an increase between $1.15 \%$ and $1.77 \%$. For the uncorrected, original data, these deviations are significantly more irregular, but again without any decisive, depth- or load-dependent trend. While the $200 \mathrm{~nm}$ and $2000 \mathrm{~nm}$ experiments exhibit increases of more than $20 \%$, the 

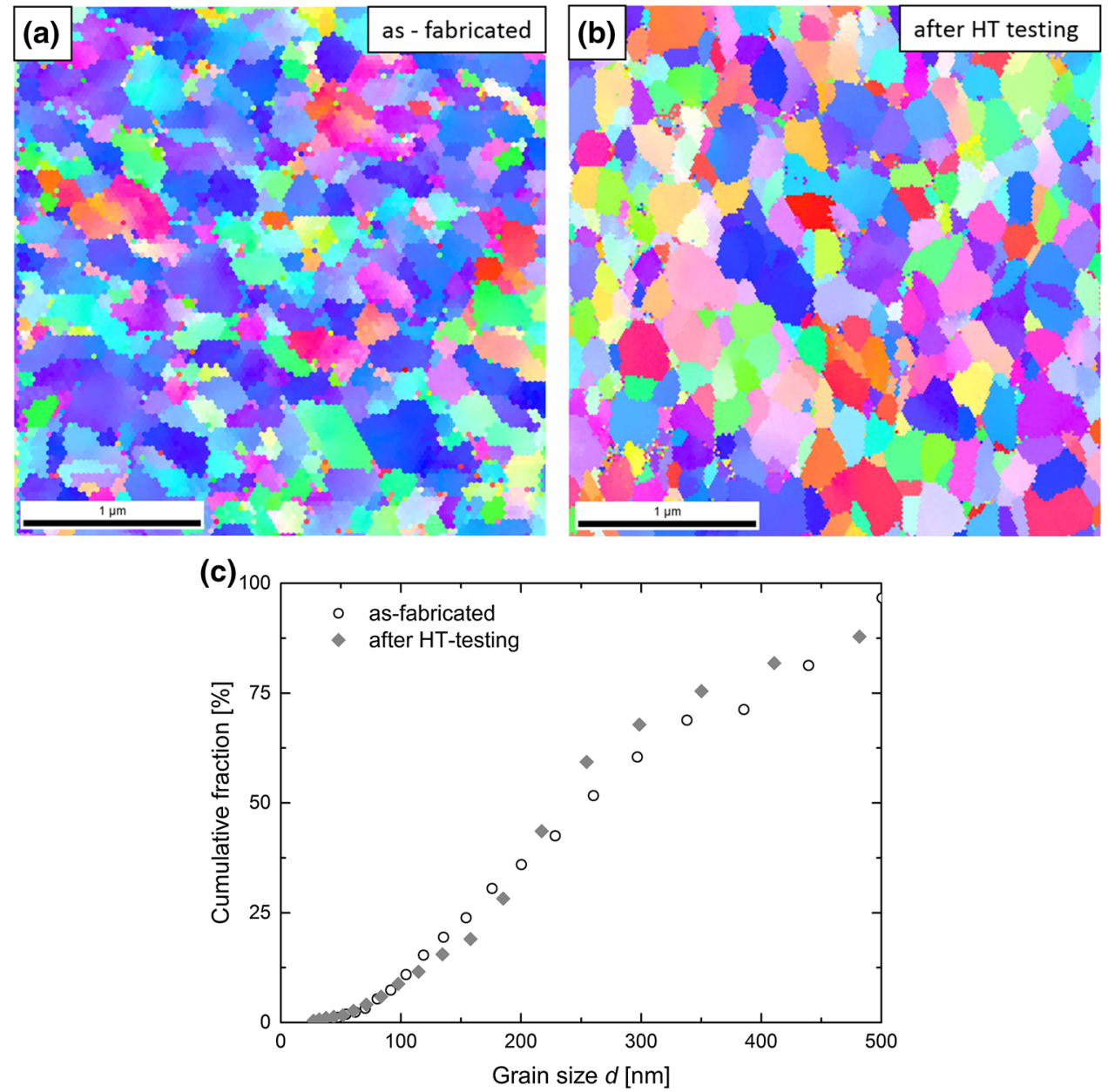

Fig. 2. Microstructure of the ufg-Au as-received and after HT-testing. (a) Inverse pole figure map of the as-fabricated material and (b) after HTindentation testing. (c) Results of the line intersection method: the median grain size is about the same for the initial as-fabricated state $(291 \mathrm{~nm} \pm 98 \mathrm{~nm})$ and the HT-state $(289 \mathrm{~nm} \pm 101 \mathrm{~nm})$.

$500 \mathrm{~nm}$ and $1000 \mathrm{~nm}$ tests range between $10 \%$ and $17 \%$. For all indentations, the temperature difference recorded with a thermocouple inside the indentation chamber changes within less than $0.1^{\circ} \mathrm{C}$ during the $2 \mathrm{~h}$ experiment, showing only very slight variations. This, however, might already influence the displacement signal. As shown in previous works, such small differences influence the overall indentation displacement for long-term experiments, ${ }^{3,23}$ since the displacement for all nanoindentation systems is not measured directly at the sample, but using a sensor inside the indenter head, which for the used system is a capacitive kind. This results in a displacement signal that is a combination of pure material answer and thermal expansion of the indenter.

In Fig. 1c, results combining different nanoindentation methods on FQ are displayed. Conventional cSR indentations agree well with cLR indentations but also with the same strain rate segments of the strain rate jump tests. Additionally, the corrected hardness over indentation depth is plotted for the different relaxation experiments described in the previous paragraph. All data agree well with each other, indicating a depth independent hardness of $9 \mathrm{GPa}$ and a very low SRS. We only noted a slightly increased hardness for small indentation depths in the relaxation experiments. The corresponding SRS is displayed in the inset of Fig. 1c, showing that fused silica exhibits only a slight SRS in a range of $0.007-0.016$. This value is consistent with recent literature, ${ }^{34}$ showing that a careful experimental design and stable environmental conditions have to be guaranteed in order to get reliable and trustable results using long term nanoindentation, even at room temperature where thermal drift issues might be considered least influential.

\section{DEFORMATION BEHAVIOR OF UFG-AU: FROM AMBIENT TO NON-AMBIENT CONDI- TIONS}

Under non-ambient conditions, thus in harsh environments relevant to, for example, areas such as energy, mobility, transportation, tooling, to name 

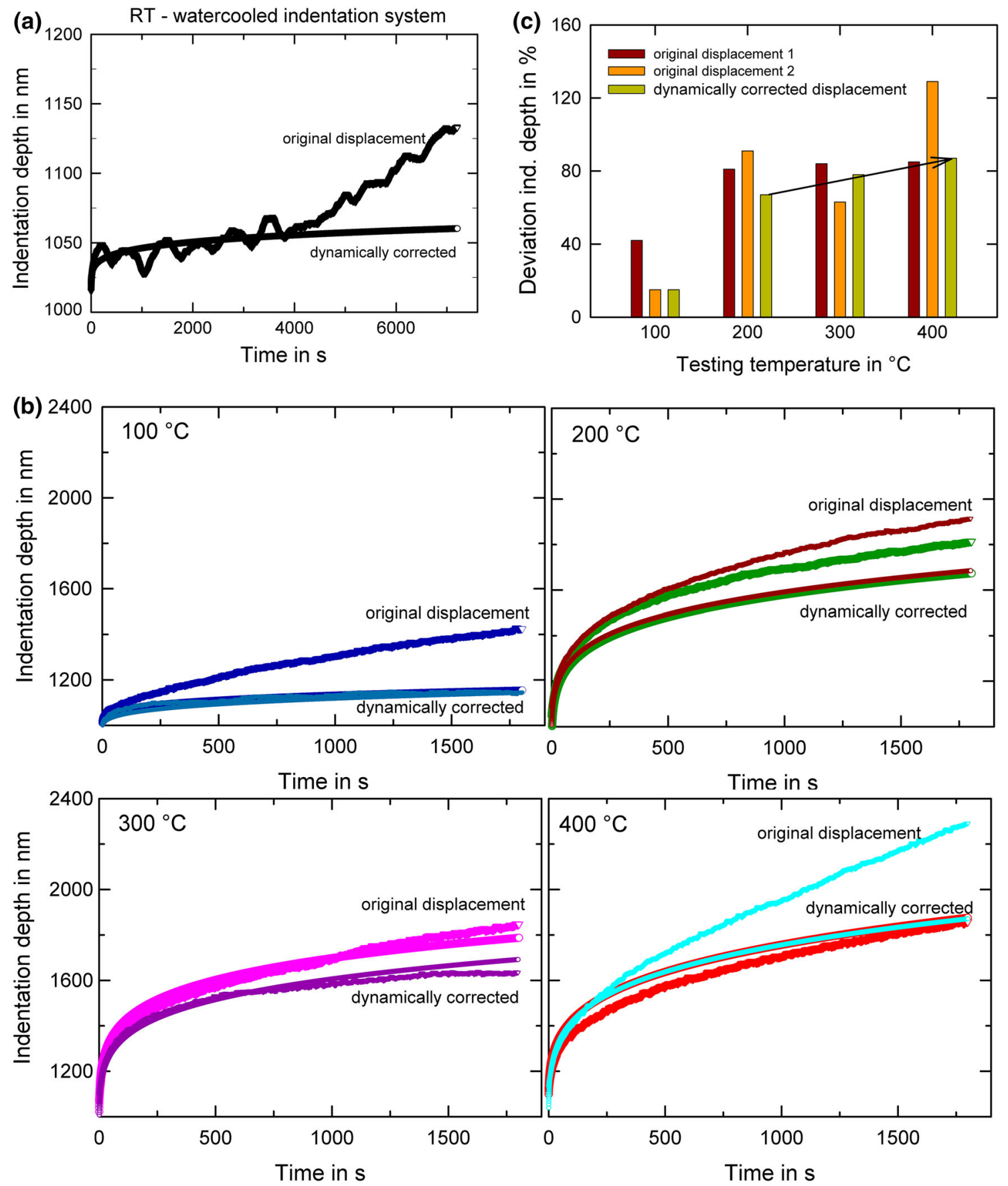

Fig. 3. Nanoindentation relaxation tests on ufg-Au starting at $1000 \mathrm{~nm}$ indentation depth for constant load times of $2 \mathrm{~h}$ or $30 \mathrm{~min}$. (a) RT, and (b) $100^{\circ} \mathrm{C}, 200^{\circ} \mathrm{C}, 300^{\circ} \mathrm{C}$, and $400^{\circ} \mathrm{C}$, showing original and dynamically corrected indentation data, respectively (with increasing creep influences with increasing T). (c) Percentage increase in indentation depth depending on temperature: original displacement of two individual indentations (left, red and middle, orange bars) and dynamically corrected (right, light green bar) displacement.

just a few, influences of thermal drift are potentially strongly intensified. In all these fields, a general trend is to create stronger materials by reducing the grain size to the ultra-fine grained or nanocrystalline regime. Therefore, ufg-Au was investigated by nanoindentation testing techniques ranging from $\mathrm{RT}$ up to $400^{\circ} \mathrm{C}$, thus up to $50 \%$ of the material melting point. As outlined before, we expected a pronounced influence of testing temperature on the deformation behavior of this ufg material, and, by choice of this noble metal, we can on purpose eliminate any other influencing factors emerging, for example, from oxidation or sample-tip interaction.

In Fig. 2, the microstructure of the HPT-deformed ufg-Au is shown before and after finalizing nanoindentation testing experiments at $400^{\circ} \mathrm{C}$, as well as the results from the line intercept method in order to quantify the microstructural changes. While the 
as-fabricated HPT material shows an initial grainsize of $291 \mathrm{~nm} \pm 98 \mathrm{~nm}$ (Fig. $2 \mathrm{a}$ and c), after HT testing and more than $10 \mathrm{~h}$ at elevated temperatures, the grain size stayed about the same around $289 \mathrm{~nm} \pm 101 \mathrm{~nm}$ (Fig. $2 \mathrm{~b}$ and c), indicating that no significant grain coarsening took place.

Besides the influence of time and temperature on the original displacement data, temperature-related changes of hardness and Young's modulus, as well as the determination of thermally activated processes, was part of the focus of this experimental part and will be discussed accordingly. The resultant raw displacements during nanoindentation relaxation experiments for $2 \mathrm{~h}$ at $\mathrm{RT}$ and $30 \mathrm{~min}$ at elevated temperatures, as well as the drift-corrected data and the percentage increase in displacement for the ufg-Au are shown in Fig. 3. At RT, the original signal is quite irregular, while the temperature inside the indenter chamber shows only a very gentle decrease from $23.03^{\circ} \mathrm{C}$ to $23.00^{\circ} \mathrm{C}$ (Fig. 3a). Since the overall environmental temperature is lowered by the cooling system by $5^{\circ} \mathrm{C}$ in comparison with the fused silica RT tests, this indicates that the water-cooling system significantly decreases the temperature inside the chamber. Moreover, this demonstrates that a small temperature change of the whole chamber is not the main origin of thermal drift, but, rather, local variations near the sample/ tip contact due to convection might influence the original displacement signal more strongly. Increasing the testing temperature, the chamber temperature remained rather constant around $23^{\circ} \mathrm{C}$ due to the water cooling unit, while tip and sample were heated to different temperatures up to $400^{\circ} \mathrm{C}$ for several hours. Note the different range of creep displacements in Fig. 3 between RT and HT experiments. The original displacement signals are again influenced by thermal drift; however, the differences between the original and corrected data is less developed compared to the not actively cooled standard stage (Fig. 1). Some of the indentations shown even exhibit no significant difference between the original and corrected data; see, for example, some $100^{\circ} \mathrm{C}$ and $400^{\circ} \mathrm{C}$ experiments. This can also be seen in Fig. 3c, where the percentage of the increase in indentation depth is plotted against temperature for original and dynamically corrected data. Again, an overall reproducible trend cannot so far be seen. We relate this to two main aspects. Firstly, there are thermally more stable conditions inside the chamber due to the active cooling of stage and cooling-shield, leading to a reduced influence of other environment issues. Secondly, the more ratedependent behavior of ufg materials leads to larger material intrinsic creep displacements, which can, for low enough drift contributions, dominate the recorded overall displacement. Notably, the original creep displacement of FQ at RT was $1050 \mathrm{~nm}$ (dynamically corrected $1015 \mathrm{~nm}$ ) after $1800 \mathrm{~s}$ (Fig. 1: $h_{\text {start }}=1000 \mathrm{~nm}$ ), while that of ufg Au was around $1050 \mathrm{~nm}$ for both datasets. It is easy to see that even

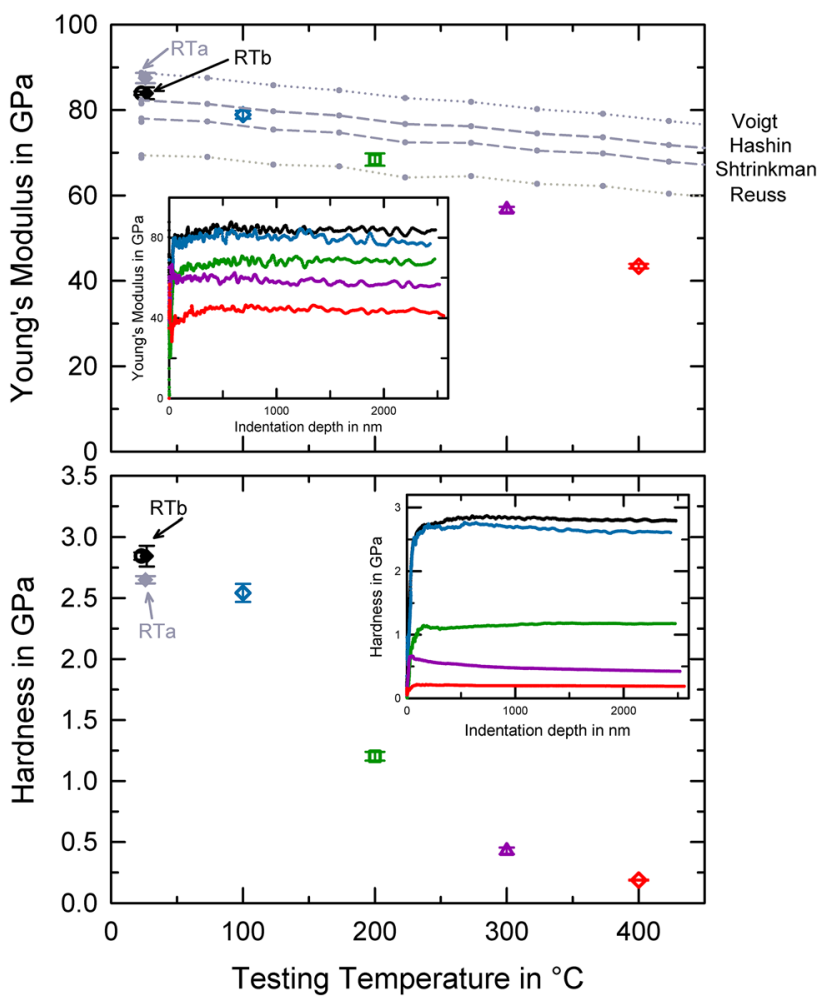

Fig. 4. Temperature-dependent mechanical properties of ufg-Au. Hardness and Young's modulus as a function of testing temperature, including literature data for sx-Au with upper and lower bounds of the Young's modulus. ${ }^{35}$ The insets show depth-dependent hardness and modulus for each temperature separately, for RT test before (RTb: black circle for sapphire tip HT setup; black rhombus diamond tip) and RT tests after HT (RTa: gray rhombus indication for diamond tip) are displayed.

a quite low constant drift rate of $\sim 0.03 \mathrm{~nm} / \mathrm{s}$ would lead to $\sim 50 \mathrm{~nm}$ drift-related displacement during the experiment. While this is already a significant fraction compared to the creep-related displacement of the strain rate-dependent ufg $\mathrm{Au}$, it is plainly clear that this hopelessly dominates over the $15 \mathrm{~nm}$ creep contribution of the FQ.

The resultant mechanical properties determined at RT and elevated temperatures are shown in Fig. 4. The Young's modulus and hardness investigated by cSR-CSM indentations (Fig. 4) both decrease with temperature, in a quite linear manner for the modulus. Thereby, the depth-dependent modulus for each indent remains constant over the indentation depth for all temperatures (see inset in Fig. 4), indicating that the machine stiffness is well calibrated and no stiffness loss in the contact was evident. Starting from $83 \mathrm{GPa}$ at RT, the modulus, $E$, of the ufg-Au decreases with increasing $T$ to $43 \mathrm{GPa}$. Cooling the sample to RT, the modulus increased back to $87 \mathrm{GPa}$. The data at RT and $100^{\circ} \mathrm{C}$ are clearly within the upper and lower bounds of the Young's modulus published in literature. ${ }^{35}$ Overcoming $200^{\circ} \mathrm{C}$, however, the modulus decreases more extensively than what would be expected from either the macroscopic polycrystalline or single 
Table I. Deviations of projected areas between software values and values determined by measurements of residual impressions with an SEM for the testing methods and temperatures used

\begin{tabular}{|c|c|c|c|c|c|}
\hline & RT (\%) & $100^{\circ} \mathrm{C}(\%)$ & $\mathbf{2 0 0}^{\circ} \mathrm{C}(\%)$ & $300^{\circ} \mathrm{C}(\%)$ & $400^{\circ} \mathrm{C}(\%)$ \\
\hline CSM & 6 & 16 & -6 & 0 & -8 \\
\hline JUMP & 12 & 14 & 13 & 10 & -9 \\
\hline CREEP & 15 & 7 & -4 & 12 & -74 \\
\hline
\end{tabular}

crystalline literature data. ${ }^{35}$ Using HT nanoindentation, Beake et al. ${ }^{4}$ reported higher modulus data for gold at temperatures of $200^{\circ} \mathrm{C}(74.1 \mathrm{GPa})$ and $400^{\circ} \mathrm{C}(68.8 \mathrm{GPa})$ compared to the present results on ufg-Au. On the other hand, using indentation experiments at RT, Kiely and Houston ${ }^{36}$ found strong anisotropy effects in the modulus of $\mathrm{Au}$, leading to differences between $85 \mathrm{GPa}$ (111), $82 \mathrm{GPa}$ (110), and $57 \mathrm{GPa}$ (001).

There are different possibilities that can be considered to explain this unexpected behavior. Firstly, in terms of a real material effect in the ufg-Au, the modulus might decrease more extensively with $T$ than for coarse-grained or single crystal materials, because the high amount of grain boundaries in the plastic zone leads to a higher compliance of the material. Generally, this was found for materials with grain sizes in the nanocrystalline regime, but has not yet, to our knowledge, been conceived for ufg materials, as the amount of grain boundary volume appears to be a quite small fraction of the total material volume for ufg grains to expect noticeable effects. ${ }^{37-39}$ A possible scenario explaining this modulus reduction above $200^{\circ} \mathrm{C}$ might be an increasing grain boundary volume with increasing temperature. This is conceivable when considering that, at these homologous temperatures exceeding 0.35 (for $\mathrm{Au}$ at $200^{\circ} \mathrm{C}$ ), climb-related accommodation processes of dislocations at grain boundaries occur ever faster, leading to an increased vacancy concentration in the grain boundaries.

Secondly, in terms of experimental reasons, some machine compliance or sample fixation problems may influence and affect the results. However, since the modulus data shown in Fig. $4 \mathrm{a}$ is constant over indentation depth for all temperatures, this seems somewhat unreasonable, as a constant modulus over temperature is generally a good indicator for a stable and reliable sample fixation. Additionally, we also tested a flat sample placed just under the indenter without fixation. In that case, as expected, a completely unreproducible and changing modulus resulted. Furthermore, we took efforts to confirm the actual residual impressions of representative indents. One indent for each temperature condition and testing method were imaged in an SEM. Subsequently, the projected area was measured using the free software ImageJ and compared to the values obtained by the nanoindenter software, NanoSuite. The deviations are represented in Table I.
This examination results in an unsystematic error with an average of $10 \%$ deviation when the $400^{\circ} \mathrm{C}$ indent is not considered (see strong required correction due to higher drift in Fig. 3). However, it must be noted that the SEM measurement of the indents is still prone to errors due to the limited possibility to determine the exact position of the rounded corners of the impressions.

However, an unassailable proof regarding experimental influences cannot be made at this point and further investigations to support our working hypothesis and to eliminate experimental concerns are on their way.

The measured material hardness as a function of testing temperature is shown in the lower part of Fig. 4. With increasing temperature, the hardness decreases from $2.8 \mathrm{GPa}$ at $\mathrm{RT}$ before testing to $0.2 \mathrm{GPa}$ at $400^{\circ} \mathrm{C}$. Nanoindentation testing at $\mathrm{RT}$ after the HT environments delivered values of 2.65 GP, slightly lower than that found for testing of the as-received material. These results fit perfectly to the microstructural evolution taking place, showing slight coarsening effects (Fig. 2). The HT data are again surprisingly low considering the slight changes observed in microstructure (Fig. 2), and also in comparison to the literature data. However, there is not an extensive body of work, as only a very few studies including HT properties of ultrafine-grained $\mathrm{Au}$ exist. Beake et al. ${ }^{4}$ investigated $\mathrm{Au}$ and reported hardness values of $0.38 \mathrm{GPa}$ at $400^{\circ} \mathrm{C}$, but the chemical composition and microstructure are not stated in this reference, which hinders a reasonable comparison. On the other hand, it is known that the hardness decrease in ufg materials can be more pronounced than in single crystal or coarse-grained materials, which is attributed to the increased SRS. This was, for example, investigated for ufg-Al and cg-Al by May et al. ${ }^{20}$ who reported that, for low strain rates of around $10^{-6} / \mathrm{s}$, the ufg-Al deformed at even lower stresses than the cg-Al reference material. Notably, for higher strain rates, this was not the case in Al.

Nonetheless, considering the constant hardness over indentation depth as shown in the lower inset of Fig. 4, and more importantly the constant modulus indicating a good quality experiment, we think that this pronounced softening at elevated temperatures has to be a material effect. As mentioned above, taking into account the large amount of grain boundaries present in the plastic zone, it is not too 


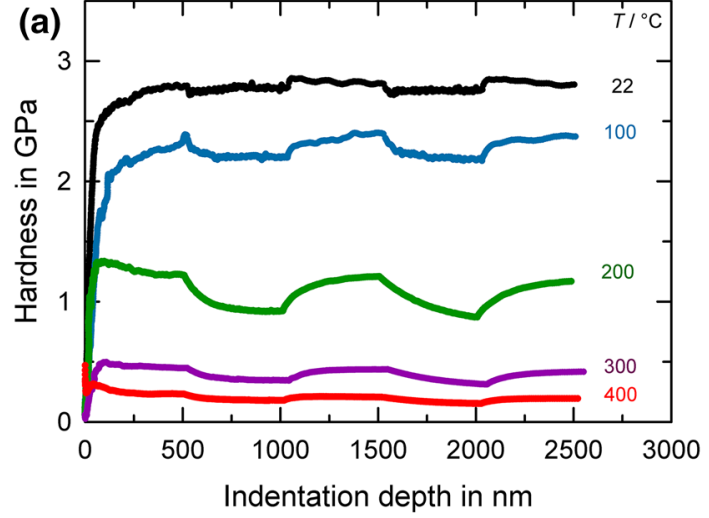

(b)

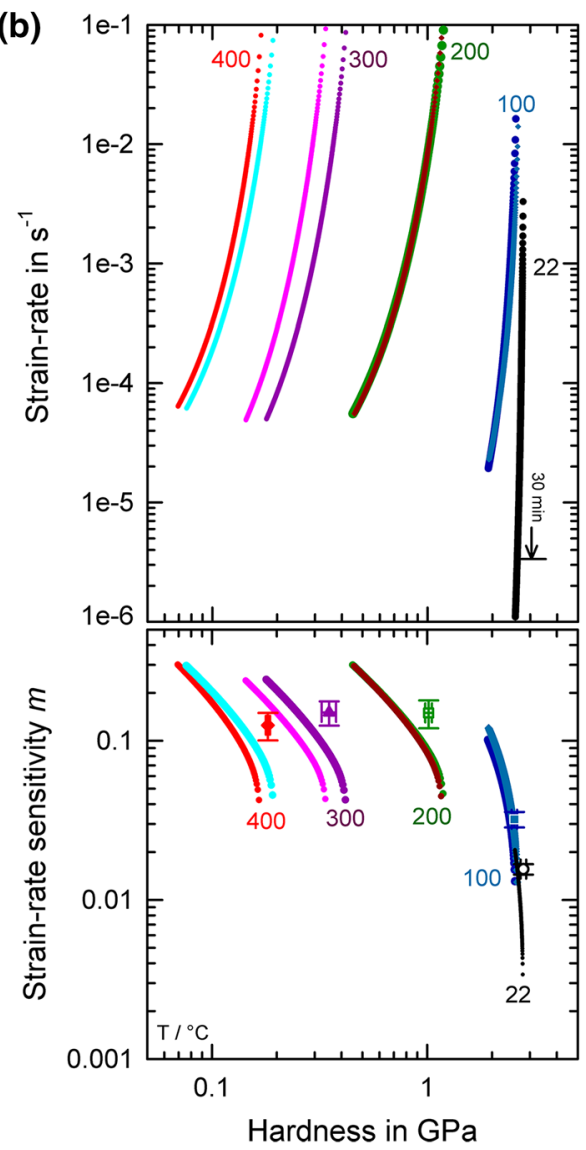

Fig. 5. Thermally activated processes in ufg-Au. (a) Nanoindentation strain rate jump tests for varying temperatures. (b) Norton plots determined from nanoindentation relaxation tests $(30 \mathrm{~min}$ holding time for HT experiments) and the corresponding time- and temperature-dependent strain rate sensitivity. Additionally, results from strain rate jump tests are included.

surprising that at elevated temperatures an increasing amount of accommodation processes takes place, thereby removing possible dislocation pile-ups and related back-stresses on dislocation sources, which effectively reduces the material hardness.

Focusing on the strain rate sensitive deformation behavior, nanoindentation strain rate jump tests were also performed for all temperatures (Fig. 5a).
Obviously, the hardness values decrease similarly to that determined in cSR-CSM indentations, but the applied strain rate changes lead to distinct jumps in the hardness along the indentation curve. With increasing temperature, these jumps not only become intensified but also the curvature describing the transient behavior changes significantly, starting with distinct jumps exhibiting negligible transient behavior at low temperatures to extensive curvatures at elevated temperatures. This behavior is in close agreement with experiments performed on ufg-Al. ${ }^{24}$ The resultant SRS $m$ is plotted in Fig. 5b combined with the dynamically corrected relaxation results (Fig. 3). The Norton plots, where the calculated creep/relaxation rates are shown as a function of the material hardness, also depict the extensive hardness decrease. With increasing temperature, the curvature becomes more pronounced, showing a more extensive hardness decrease paired with higher relaxation rates. For each testing temperature, two different indents are shown which are mostly in good accordance to each other (only $T=300^{\circ} \mathrm{C}$ shows a small discrepancy). The corresponding SRS, $m$, which is evaluated from the slope of the Norton plot, is shown in the lower part of Fig. 5b. It is seen that $m$ increases with increasing testing time as well as increasing testing temperature. Moreover, the slope of the creep curve is intensified at higher $T$, leading to higher $m$ values. Additionally, the SRS determined using strain rate jump tests (Fig. 5a) is also plotted. For all temperatures, it appears that the hardness values are in good accordance between the two testing methodologies; however, for higher $T$, relaxation tests lead to slightly lower SRS values at similar hardness levels. This could be due to some difference in microstructure, but is more probably due to different applied strain rates during both testing techniques.

What is interesting to note with respect to the temperature-dependent deformation behavior of the ufg-Au is that, at temperatures $\geq 200^{\circ} \mathrm{C}$, the SRS is substantially increased by an order of magnitude compared to the $\mathrm{RT}$ value, almost reaching values found for superplastic deformation behavior. ${ }^{40}$ This again indicates a pronounced increase in thermally activated accommodation processes of dislocations at grain boundaries. Moreover, this also corresponds to the temperature at which we observed an increased reduction of the elastic modulus, which would support our working hypothesis regarding the modulus reduction at elevated temperatures by increased grain boundary volume.

From a broader perspective, the rate-dependent behavior is in good agreement with other reports on fcc ufg materials in the literature. Reference data for pure ufg-Au itself are very rare, ${ }^{41,42}$ since only a limited number of studies have been performed to date. Merle et al. ${ }^{41}$ recently found significantly higher $m$ values for nc $\mathrm{Au}$ films investigated via small-scale bulge testing. However, there were some 
differences in the materials' purity, since the tested material was highly pure and additionally in the form of a $\sim 300$-nm-thick free-standing film in nature. Investigating an $\mathrm{Au}$ film supported by a $\mathrm{SiN}_{x}$ substrate, the SRS was found to be in the same range as in this study. Moreover our material is, owing to the powder production route, not as pure as the thermally evaporated $\mathrm{Au}$ coated on $\mathrm{SiN}_{x}$. However, Nyakiti et al. ${ }^{42}$ investigated different $\mathrm{Au}$ $\mathrm{Cu}$ alloys and found for $\mathrm{Au}$ with only $1 \mathrm{wt} . \% \mathrm{Cu}$ similar SRS as in our tests. This seems reasonable, since via our chosen production route, small amounts of $\mathrm{Cu}$ are incorporated as impurities. In order to allow a further comparison with other fcc materials, ufg-Cu seems to be a reasonable choice, since the melting point and thus the homologous temperature of both are almost the same. Generally, for ufg- $\mathrm{Cu}$, a quantitatively similar behavior has been reported, ${ }^{21}$ relating the increased SRS with thermal activation of dislocation motion and their annihilation at high-angle grain boundaries.

\section{CRITICAL REMARKS AND OUTLOOK: INFLUENCES DURING ELEVATED TEM- PERATURE LONG-TERM NANOINDENTA- TION}

Generally, we want to emphasize that a profound knowledge about the environmental conditions, but also a reliable and robust control of the stability of the testing system itself over time and temperature, is crucial. As shown in this work, but also already stated in the literature several times before, small changes in the local temperature might lead to significant errors in the displacement signal of the system. This obviously becomes more pronounced the longer the measurement takes, thereby natively affecting relaxation kinds of experiments more severely. While the choice of materials used here was deliberately to avoid environmental effects, influencing environmental conditions such as oxidation or tip degradation must be kept in mind in order to allow a useful and meaningful discussion of nanoindentation results under non-ambient conditions. Although we deliberately avoided any other factors, it turns out that just the influence of local thermal drift itself results in completely irregular material response with no correlation between creep displacement, creep depth, or contact area. This time-dependent variation of local drift rates can, in our opinion, be efficiently dealt with by using a continuously recorded contact stiffness, such as the CSM or CMX techniques, to correct for the true contact area. Vice versa, long-term data without this kind of correction possibility should be considered critically. For future developments and a deeper understanding of possible machine effects, it would be interesting to compare well-characterized reference materials such as the ones used in this work on different platforms using a defined set of testing protocols.
Turning to the HT experiments, the drift influences remain the same. The only difference is that the SRS typically increases with temperature, which means from a practical point of view that larger creep displacements will occur, while the drift contribution might remain similar, which gives a better ratio between material contribution versus drift influence to the total displacement measured. There appears to still be some difference between jump tests and creep tests, but this might relate to the different stresses and strain rates where the SRS was derived. This can be improved by experimental design and data analysis.

Aiming for ever increasing temperatures, it is clear that oxidation and tip interaction will be the main challenges, and possibly the most promising direction is moving towards vacuum conditions. Still, remaining drift influences will occur and will require correction. Thus, as CSM seems to be a potent method for doing so, it might be worth looking carefully for possible influences of the CSM data versus static nanoindentation data for all indentation depths.

\section{ACKNOWLEDGEMENTS}

The authors acknowledge funding by the European Research Council under Grant number: 340185 (V. M. and R. P.) as well as by the FWF Project "P-25325" (D. K.). Further financial support by the Austrian Federal Government (837900) (in particular from the Bundesministerium für Verkehr, Innovation und Technologie and the Bundesministerium für Wirtschaft, Familie und Jugend) represented by Österreichische Forschungsförderungsgesellschaft $\mathrm{mbH}$ and the Styrian and the Tyrolean Provincial Government, represented by Steirische Wirtschaftsförderungsgesellschaft $\mathrm{mbH}$ and Standortagentur Tirol, within the framework of the COMET Funding Programme is appreciated.

\section{OPEN ACCESS}

This article is distributed under the terms of the Creative Commons Attribution 4.0 International License (http://creativecommons.org/licenses/by/4.0/), which permits unrestricted use, distribution, and reproduction in any medium, provided you give appropriate credit to the original author(s) and the source, provide a link to the Creative Commons license, and indicate if changes were made.

\section{REFERENCES}

1. M.J. Mayo and W.D. Nix, Acta Metall. 36, 2183 (1988).

2. R. Schwaiger, B. Moser, M. Dao, N. Chollacoop, and S. Suresh, Acta Mater. 51, 5159 (2003).

3. K. Durst and V. Maier, Curr. Opin. Solid State Mater. Sci. (2015). doi:10.1016/j.cossms.2015.02.001.

4. B. Beake and J.F. Smith, Philos. Mag. A 82, 2179 (2002).

5. Z.C. Duan and A. Hodge, JOM 61, 32 (2009).

6. S. Korte, R.J. Stearn, J.M. Wheeler, and W.J. Clegg, J. Mater. Res. 27, 167 (2012).

7. J.M. Wheeler and J. Michler, Rev. Sci. Inst. 84, 045103 (2013).

8. A. Barnoush and H. Vehoff, Corr. Sci. 50, 259 (2008).

9. O. Franke, M. Göken, and A. Hodge, JOM 60, 49 (2008). 
10. J.M. Wheeler, D. Armstrong, W. Heinz, and R. Schwaiger, Curr. Opin. Solid State Mater. Sci. (2015).

11. J.M. Wheeler and J. Michler, Rev. Sci. Inst. 84, 101301 (2013).

12. M. Kreuzeder, M.D. Abad, M.M. Primorac, P. Hosemann, V. Maier, and D. Kiener, J. Mater. Sci. 50, 634 (2015).

13. J. Nohava, N.X. Randall, and N. Conte, J. Mater. Res. 24, 873 (2009).

14. R.Z. Valiev, I.V. Alexandrov, Y.T. Zhu, and T.C. Lowe, J. Mater. Res. 17, 58 (2002).

15. H.W. Höppel, J. May, P. Eisenlohr, and M. Göken, Z. Metallkunde 96, 566 (2005).

16. Q. Wei, S. Cheng, K.T. Ramesh, and E. Ma, Mater. Sci. Eng. A 381, 71 (2004).

17. Q. Wei, J. Mater. Sci. 42, 1709 (2007).

18. M. Dao, L. Lu, R.J. Asaro, J.T.M. De Hosson, and E. Ma, Acta Mater. 55, 4041 (2007).

19. M.A. Meyers, A. Mishra, and D.J. Benson, Prog. Mater Sci. 54,427 (2006)

20. J. May, H.W. Höppel, and M. Göken, Scr. Mater. 53, 189 (2005).

21. J. Bach, J.-P. Liebig, H.W. Höppel, and W. Blum, Philos. Mag. 93, 4331 (2013)

22. W. Blum and X.H. Zeng, Acta Mater. 57, 941 (1966-2009).

23. V. Maier, B. Merle, M. Göken, and K. Durst, J. Mater. Res. 28, 1177 (2013).

24. J.M. Wheeler, V. Maier, K. Durst, M. Göken, and J. Michler, Mater. Sci. Eng. A 585, 108 (2013).

25. V. Maier, A. Hohenwarter, R. Pippan, and D. Kiener, Scr. Mater. 106, 42 (2015)
26. A. Bachmaier and R. Pippan, Int. Mater. Rev. 58, 41 (2013).

27. A. Bachmaier, A. Hohenwarter, and R. Pippan, Scr. Mater. 61, 1016 (2009).

28. W.C. Oliver and G.M. Pharr, J. Mater. Res. 7, 1564 (1992).

29. V. Maier, K. Durst, J. Mueller, B. Backer, H.W. Höppel, and M. Göken, J. Mater. Res. 26, 1421 (2011).

30. B.N. Lucas and W.C. Oliver, Metal. Mater. Trans. A 30A, 601 (1999).

31. T.P. Weihs and J.B. Pethica, Mater. Res. Soc. Symp. 239, 325 (1992).

32. S.A. Syed Asif and J.B. Pethica, Philos. Mag. A 76, 1105 (1997).

33. M.J. Cordill, M.S. Lund, J. Parker, C. Leighton, A.K. Nair, D. Farkas, N.R. Moody, and W.W. Gerberich, Int. J. Plast. 25, 2045 (2009).

34. R. Limbach, B.P. Rodrigues, and L. Wodrazeck, J. NonCryst. Sol. 404, 124 (2014).

35. G. Simmons and H. Wang, Single crystalline elastic constants and calculated aggregate properties: a handbook (Cambridge: MIT Press, 1971).

36. J.D. Kiely and J.E. Houston, Phys. Rev. B 57, 12588 (1998),

37. H. Gleiter, Prog. Mater. Sci. 33, 223 (1989).

38. H. van Swygenhoven, M. Spaczer, and A. Caro, Acta Mater. 47, 3117 (1999).

39. J. Schiøtz and K.W. Jacobsen, Science 301, 1357 (2003).

40. T.C. Langdon, Met. Mater. Trans. A 13A, 689 (1982),

41. B. Merle, D. Cassel, and M. Göken, J. Mater. Res. 30, 2161 (2015).

42. L.O. Nyakiti and A.F. Jankowski, Metal. Mater. Trans. A 41A, 838 (2010). 